\title{
Significance of Variations Within the Lepromatous Group*
}

\author{
D. S. RIDLEY \\ Hospital for Tropical Diseases, 4 St Pancras Way, London, N.W.1 \\ M. F. R. WATERS \\ Leprosy Research C'nit, Sunyen Buloh Leprosarium, Sunyei Buloh, Selangor, Malaysia \\ and \\ National Institute for Medical Research, Mill Hill, London, N.W.7
}

\begin{abstract}
To the 5 classes of lepromatous leprosy defined by Ridley and Jopling (1966) the authors now add a sub-group, LI (Indefinite Leproma), which appears to occur most frequently among Chinese and Malay patients but has been seen in patients of many other races. The biological response to treatment of this sub-group is described.
\end{abstract}

\section{INTRODUCTION}

Patients in the Leprosy Research Unit at Sungei Buloh have for the last 10 years been classified on the 5-group TT-LL system (Ridley and Jopling, 1962, 1966). From an early stage it was clear that the histological and clinical picture of lepromatous leprosy as seen in Malaya (West Malaysia) differed in some respects from that of typical polar lepromatous (LL) patients, although the typical LL form was occasionally encountered. It was also known that the rate of fall of the biopsy index (Ridley, 1958 a) was somewhat faster in Malayan patients than in Europeans, namely, $33 \%$ as against $25 \%$ for each period of 6 months (Ridley, 19586; Ridley and Jopling, 1962). Nevertheless, lepromatous patients at Sungei Buloh continued to be classified as LI, for a number of reasons: (1) histologically the majority were closer to LL than to the next group, BL; (2) they were highly bacilliferous and the rate of fall of the bacterial index (BI) in smears was consistent with LL; (3) clinically they were either consistent with LL or closer to IL than to BL; (4) they commonly developed erythema nodosum leprosum (ENL), sometimes of a severe form; and (5) most of them remained stable during therapeutic trials of 6 months' or a

*Received for publication 17 June, 1969. year's duration. More recently, however, when greater numbers of such patients were studied, and also were followed-up for longer periods, it became evident that an appreciable proportion were undergoing reversal reactions with a significant effect upon prognosis: there is an immunological shift in the direction of tuberculoid, followed by an increase in the rate of elimination of bacilli from the skin, with or without an obvious reaction in the lesions (Fernandez et al., 1962; Ridley, 1969). Such reactions were previously regarded as a feature of borderline leprosy (BL or $\mathrm{BB}$ ) and were an important reason why BL patients were not accepted for therapeutic trials (Ridley and Jopling, 1966; Waters et al., 1967). It became necessary therefore to make a thorough analysis of the "Malayan" type of leproma (which incidentally is not exclusive to Malaysia) and for this purpose a sub-group called Indefinite Leproma (LI) was introduced. Although the LI sub-group was originally a histological concept, it was soon found that the majority of cases could be identified clinically.

\section{MATERIALS AND METHODS}

The following steps were taken. (1) After a preliminary trial run with the modified classification and a comparison of the clinical and 
histological diagnoses, all new patients admitted to the Leprosy Research Unit, Sungei Buloh, were classified on the new system. Each was placed in one of the five original groups, or in the new LI sub-group. (2) Former patients at Sungei Buloh Leprosarium who had taken part in 2 trials were re-classified on the basis of their clinical records and the histological findings in sections, and their subsequent progress rates were estimated by the logarithmic index of bacilli (LIB) in biopsy specimens (Ridley and Hilson, 1967). The 2 trials were of ditophal (Etisul) and DDS, as against DDS alone (Waters and Pettit, 1965) and DDS in low dosage (Pettit and Rees, 1967). They were chosen because patients in these trials had been followed up for a year. As there was no difference in the rates of fall of the LIB in the 2 trials the results were treated as a uniform series for the present purpose. (3) Patients, both past and present, at the Jordan Hospital, Redhill, England, were reclassified on the basis of their histological sections, but not clinically, and their progress rates under treatment were estimated by the LIB. All patients who had been followed-up for a period of at least 18 months, and whose lesions had a granuloma fraction of at least 0.2, were included in the analysis. All had been treated with sulphones or thiambutosine (Ciba 1906, DPT). (4) The distribution of patients among the 5 groups and one sub-group was calculated according to race. The great majority of Sungei Buloh patients were Chinese or Malay; those at the Jordan Hospital were predominantly of European or Eurasian origin, but there were also some patients of Indian, Negro, and other races. (5) The progress rates of patients in the different groups were compared. Although the LIB was regarded as the most useful index for this type of work, the bacteriologica! index (BI) and morphological index (MI) of smears were also noted.

\section{DEFINITION OF THE LI SUB-GROUP}

\section{Clinical}

The majority of patients present an appearance closely resembling Ll, leprosy. Alnıst all

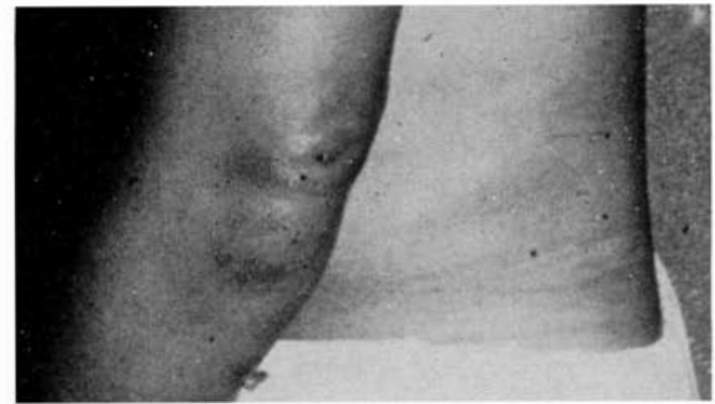

FIG.

Borderline lesion on left arm of patient who subsequently developed LI leprosy.

the lesions are lepromatous and symmetrical, and the smears are strongly positive. Infiltration may be heavy. However, on careful inspection, nearly always one or a small number of residual, asymmetrical, borderline lesions (BB type) may be detected (Fig. 1). The latter appear months or years before the lepromatous lesions; they are most commonly found on the lower limbs, although they may occur elsewhere on the bory, especially on the extensor surfaces of the trunk and arms. The outer edge of such a residual borderline lesion is usually somewhat vague as a result of the surrounding lepromatous infiltiation, but the inner edge may remain sharp with a small hollowed-out, hypopigmented, anaesthetic centre. In addition there may be asymmetrical nerve damage, e.g. a unilateral claw hand or drop foot; the nerve damage of ten occurs early, in association with a borderline lesion (Fig. 2) and before the onset of the symmetrical lepromatous lesions, but occasionally it develops much later in an asymmetrically-enlarged nerve, when the treated patient is suffering from FNL. The outer halves of the eyebrows are usually intact and the nasal cartilage and bone are often spared. However, the testis is frequently involved and leprous orchitis (usually associated with ENL) may occur; although true gynaecomastia is rare, pseudogynaecomastia due to heavy infiltration of the skin of the nipple without glandular enlargement of the breast has occasionally been noted. 


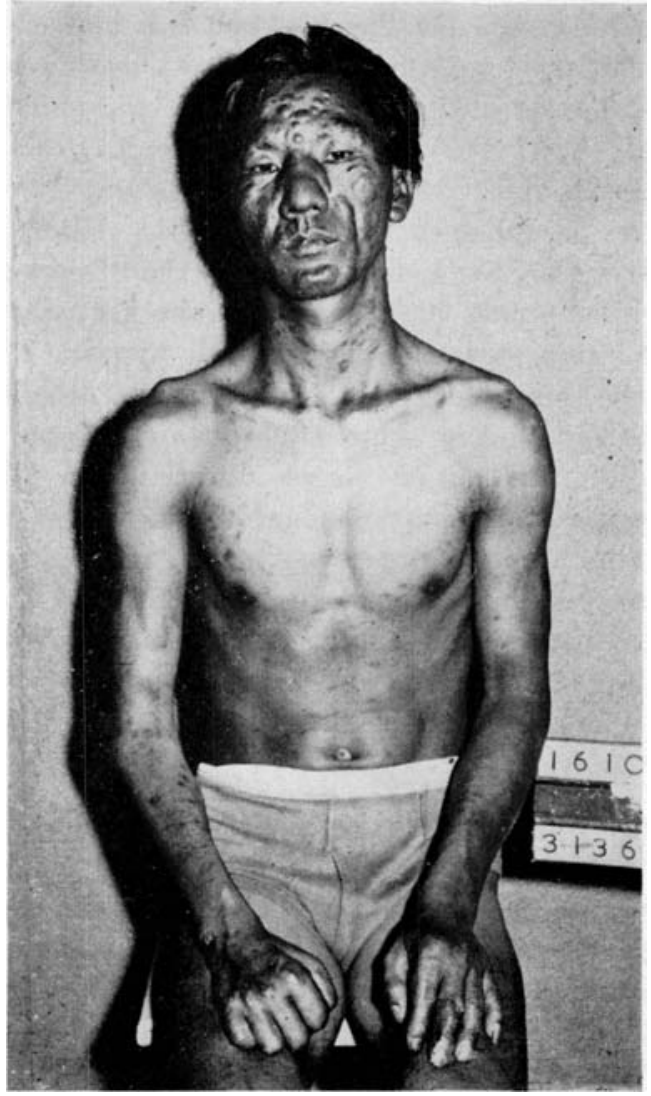

FIG. 2

Residual borderline (BT or BB) annular lesion encircling the right forearm; the distal (inner) edge remains sharp but the proximal (outer) edge is merged into the lepromatous infiltrate; the right hand is clawed with radial, ulnar, and median nerve paralysis. The borderline lesion and the nerve paralysis developed 7 years before the patient presented for treatment; at that time he had been developing LI lesions for the previous year, and some LI papules are visible on the right forearm.

Some Chinese patients of the LI type, especially young adult males, show remarkably little deformity of the face; their ears are not enlarged (although a few tiny papules may be present), the eyebrows and nose are intact, and obvious lesions on the face are minimal (Fig. 3). Nevertheless, smears from the ear lobes are symmetrically and strongly positive provided that the lepromatous lesions have been present on the trunk and/or limbs for more than just a few weeks. In general, this "small-eared" type of lepromatous leprosy is of recent onset,

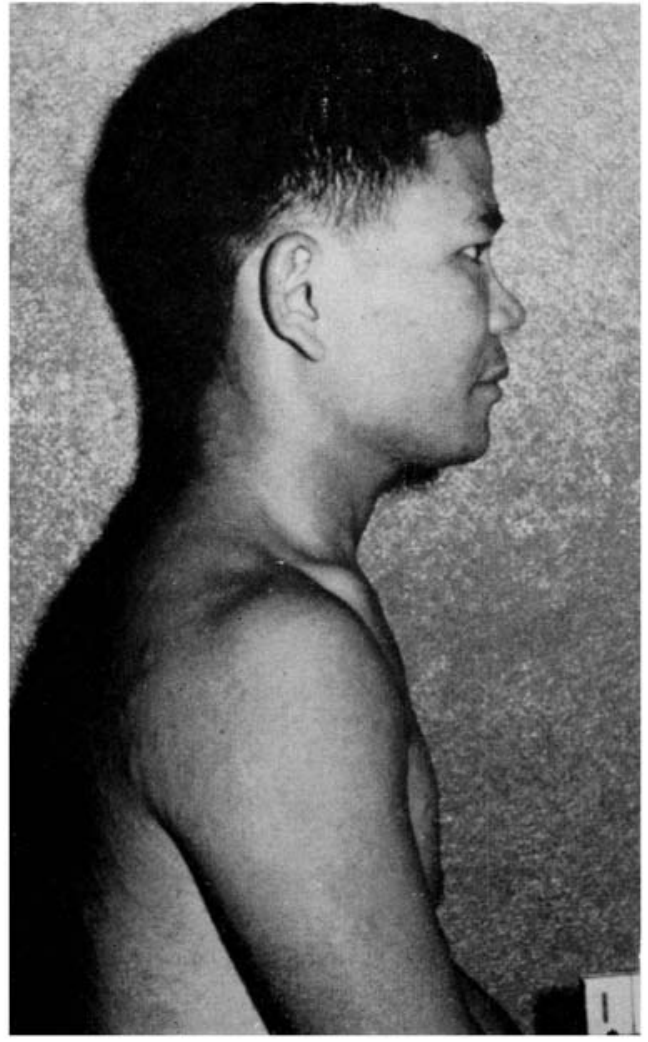

FIG. 3

Recently developed LI leprosy, with no appreciable enlargement of the ears and few lesions on the face. Eyebrows and nose are intact.

associated with rapid multiplication of leprosy bacilli throughout the skin; if treatment is delayed for 2 to 3 months then the BI and the degree of infiltration are both considerably increased. Furthermore, under treatment these patients may revelop severe ENL, even though they bear so few of the stigmata of lepromatous leprosy.

A third clinical type which is occasionally seen, more especially in older patients, is completely symmetrical. The face is mildly infiltrated, the ear lobes enlarged, and the trunk and limbs covered with multiple, erythematous, lepromatous macules or flat papules. However, the degree of underlying infiltration is relatively slight, the skin being less "succulent" than is typical of LL leprosy (Fig. 4). Such patients are 


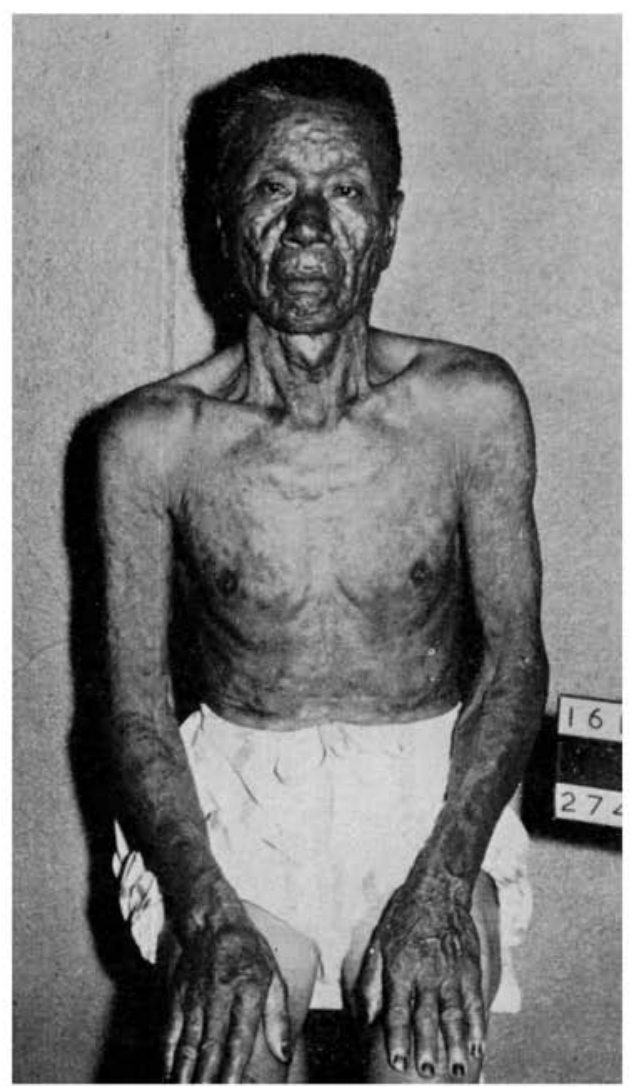

FIG. 4

Symmetrical, erythematous, LI maculo-papules, but with only slight infiltrate in the "normal" skin between the lesions.

difficult to classify clinically, although careful examination may reveal an asymmetrical anaesthetic area; histological diagnosis is essential to place them accurately on the leprosy spectrum.

\section{Histological}

As previously reported, the BL group is distinguished from the LL group either by an epithelioid tendency in the host cells of the bacilli, or by an increase in the number of lymphocytes in the granuloma. In addition, in BL there may or may not be a cuff of lymphocytes around nerves.

The same 3 characteristics are used to define the LI group. (1) The host-cell is a histiocyte. In the most active stage it takes the form of a macrophage, which is typically less rounded than the macrophage in active LL. Compression and flattening of the sides may give it some resemblance to an epithelioid cell. As it matures (a less active phase of the granuloma can sometimes be observed in another part of the same section), the host-cell appears as a fairly large histiocyte with no epithelioid tendency and no appreciable foamy change. In chronic lesions of longer duration, or after treatment, a foamy change occurs, though the accumulation of fat is not as great as in the corresponding stage of an LL lesion and there is less necrosis of the fatty cells in the granuloma. If large globi develop they are usually engulfed in a multinucleate giant-cell with fairly fleshy cytoplasm.

(2) Alternatively, or sometimes in addition to the above, there is an increase of lymphocytes in the granuloma. The number of these cells is then greater than would be found in an LL lesion but not great enough to justify a classification of BL. These lymphocytes are diffusely and fairly evenly infiltrated throughout the granuloma. Plasma cells are often fairly numerous and are a feature of LI lesions, though they are not a reliable diagnostic criterion. The mixture of histiocytes, lymphocytes, and plasma cells in the granuloma presents a pleomorphic picture which, together with its cellularity, is the most characteristic feature of Ll (a lesion of this type is illustrated in Fig. 21 of Ridley and Jopling, 1966).

(3) The nerves in LI lesions, as in BL, may show nothing but fibrosis or loss of structure due to active involvement during an earlier borderline stage of the infection. More typically the nerves in LI cases, close to BL, are characterized by infiltration of the perineurium, though not of the nerve bundle itself, with histiocytes heavily laden with bacilli. In cases of LI near to LL, the infiltration disappears and the nerve sheath is split by vacuolar spaces, which presumably are due to disintegration of the histiocytic cells. Perineural infiltration is sometimes observed 
also in BL patients, though it tends to be obscured by the cuff of lymphocytes around the affected nerve-bundle. In LL cases the perineural sheath is almost always normal.

There is, of course, no absolute point of distinction between LL and LI, or LI and BL and considerable experience of classification on this basis is needed before reproducible results are obtained. It is helpful to keep a small collection of classified slides as standards. There are two mains points of difficulty: (1) In very active lesions the histology, superficially at least, has a more borderline appearance than in less active ones. In LL cases there is merely an absence of fatty change in the swollen macrophages. In LI patients, however, the most heavily laden cells at the centre of a very active lesion may take on a somewhat epithelioid appearance. In BL one occasionally sees foci almost indistinguishable from epithelioid cell foci, except for the fact that they are found to be exceptionally heavily stuffed with bacilli, whereas in a true epithelioid cell focus bacilli would be fewer than elsewhere. There is a dual spectrum in histology, of BL to LL and of activity to regression. Allowance has to be made for the one in evaluating the other. (2) The foregoing account, although it describes both active and regressing lesions, refers mainly to untreated patients. After treatment the lesions regress in the manner described, but the histology is liable to be complicated by reactions which are usually associated with the influx of some lymphocytes at some stage (the possibility that reactions may occur in untreated patients must not be forgotten). In general, it should be quite possible to make a "blind" histological classification of an untreated patient; but if the patient has been treated it is desirable that the histologist should know this, and if possible that he should know the pre-treatment classification.

It is exceptional to find that the histological classification of 2 lesions taken at the same time from the same patient differs by as much as one group, when classification is based on a 5-group system, except possibly during a reversal reaction. When the LI sub-group is introduced it does happen occasionally that the classification of two concurrent biopsies differs; e.g. one may be LI and the other BL, even when there is no reaction. However, this is observed on less than 1 in 10 occasions.

\section{RESULTS}

Clinical-histological correlation in classification

Sections were available from 122 untreated patients at the Jordan Hospital. An equal number of patients were taken from the most recent admissions to Sungei Buloh, and of these the original clinical classification was available for 33 patients in the LL-BL, range. There was complete histological-clinical agreement in 17 of the 33; and partial agreement in a further 11 cases in which there was some doubt on the clinical side, e.g. the clinical classification was given as LI or BL and the histological classification was one of these groups. There was disagreement in 5 cases concerning 2 adjacent groups, e.g. BL and LI, but in no case was there a disagreement concerning BL and LL. In cases of doubt the histological classification was accepted, partly because it appeared to be a little more emphatic than the clinical classification, and partly because at the Jordan Hospital clinical classification using the LI sub-group had not so far been undertaken.

Proportion of LI patients in different races

The distribution of patients between the 6 groups at Sungei Buloh Leprosarium and at the Jordan Hospital is shown in Table 1,

TABI,E 1

Distribution of patients in 6 classification groups, at the Jordan Hospital and at Sungei Buloh Leprosarium, and according to race.

\begin{tabular}{lrrrrrrr}
\hline & $L L$ & $L I$ & $B L$ & $B B$ & $B T$ & $T T$ & Total \\
\hline Jordan Hospital & 30 & 26 & 20 & 13 & 25 & 8 & 122 \\
Sungei Buloh & 15 & 51 & 19 & 10 & 21 & 6 & 122 \\
\hline Chinese & 8 & 26 & 8 & & & & \\
Malay & 4 & 22 & 6 & & & & \\
Indian & 8 & 10 & 8 & & & & \\
European & 20 & 15 & 8 & & & & \\
Others & 5 & 4 & 9 & & & & \\
Total & 45 & 77 & 39 & 23 & 46 & 14 & 244 \\
\hline
\end{tabular}


TABLE 2

Analysis of the mean falls of the logarithmic biopsy index (LIB) after treatment for 1 year, and in the 6 months following a reversal reaction

\begin{tabular}{|c|c|c|c|c|c|c|c|c|c|}
\hline \multirow[t]{2}{*}{$\begin{array}{l}\text { Leprosy } \\
\text { group }\end{array}$} & \multicolumn{3}{|c|}{ No. of patients } & \multicolumn{3}{|c|}{$\begin{array}{c}\text { Mean fall in } L I B \\
\text { at one year }\end{array}$} & \multicolumn{2}{|c|}{$\begin{array}{c}\% \text { incidence of reversal } \\
\text { reaction after }\end{array}$} & \multirow{2}{*}{$\begin{array}{l}\text { Fall in LI B in the } 6 \text { months } \\
\text { following reversal reaction }\end{array}$} \\
\hline & $S . B .^{*}$ & J.H. & Total & $S . B$. & J.H. & Mean & $1 y r$ & 2-7 yr follow-up & \\
\hline LI & 40 & 18 & 58 & 0.64 & 0.56 & 0.60 & 10 & 21 & 1.8 \\
\hline BL & 19 & 6 & 25 & 2.2 & 2.2 & 2.2 & 36 & 60 & 2.1 \\
\hline
\end{tabular}

* S.B., Sungei Buloh Leprosarium patients; J.H., Jordan Hospital patients.

which also shows the breakdown of patients from both centres according to race. The LL: LI ratio among European and Eurasian patients is $1: 0.75$; among Chinese and Malays it is 1: 4; among those of Indian origin the ratio appears to fall between these 2 extremes, but the numbers are too small to give an accurate figure. At Sungei Buloh as expected, the proportion of LI patients appears to be exceptionally high by world standards, though there are other races about which more information is needed.

\section{Rute of fall of $L I B$ in $L L, L I$ and BL patients}

The fall of the LIB after one year's treatment is a little over 3 times greater in LI than in LL patients, and a little over 3 times greater in BL than LI (Table 2). Thus LI would appear to be a truly intermediate group, though numerically the fall in LIB for LI is closer to that for LL than for BL. The patients at Sungei Buloh Leprosarium and the Jordan Hospital could be compared, from the point of view of the fall in the LIB, only at one year. At this time there was good agreement in the results. The fall in LL and LI patients was marginally higher at Sungei Buloh than at the Jordan, showing that there was no bias in classifying patients as LI at Sungei Buloh and LL at the Jordan, possibly rather the reverse, although an alternative explanation lies in the different methods employed at the 2 hospitals for the treatment of ENL; in either case the differences are not statistically significant.

The fall of the LIB during the course of reatment is shown in Table 3 (these results
TABLE 3

Analysis of the mean fall in the LIB during treatment (Jordan Hospital patients only)

\begin{tabular}{|c|c|c|c|c|c|c|c|c|c|}
\hline \multirow{2}{*}{\multicolumn{2}{|c|}{$\begin{array}{c}\text { Initial } \\
\text { LIB }\end{array}$}} & \multicolumn{8}{|c|}{ Mean fall in LIB at $(y r)$} \\
\hline & & $\frac{1}{2}$ & 1 & $1 \frac{1}{2}$ & 2 & $2 \frac{1}{2}$ & 3 & $3 \frac{1}{2}$ & 4 \\
\hline $\mathrm{LL}$ & 5.27 & 0.06 & 0.13 & 0.34 & 0.80 & 0.81 & 1.2 & 1.8 & 2.5 \\
\hline $\mathrm{L}, \mathrm{I}$ & 5.28 & 0.17 & 0.56 & 1.1 & 1.3 & 1.9 & 2.8 & & \\
\hline $\mathrm{BL}$ & 4.8 & 1.5 & 2.2 & 3.9 & & & & & \\
\hline
\end{tabular}

were available only for the Jordan Hospital patients). The rate of fall in the 3 groups bears a constant relationship throughout the period of treatment during which biopsies were made. These conclusions were supported in the main by the results of the BI in the same patients' smears. But it was not possible to detect any significant difference between the LL, LI, and BL groups in respect of the rate of fall of the MI during the early stage of treatment.

\section{Reversal reactions}

The incidence of reversal reactions in the 3 groups is given in Table 2 . The number in LI patients was relatively small; during the first year they occurred in 6 out of 58 patients, or $10 \%$, of whom 2 showed only histological evidence of reversal; and on more prolonged follow-up there were a further 6 cases. Reversal reactions occurred more frequently in BL patients; they tended to be clinically more severe than in LI leprosy and to develop earlier in treatment $(9$ out of $25 \mathrm{BL}$ patients, i.e. $36 \%$, reacted within 6 months of starting treatment and a further 6 out of $25(24 \%)$ after more than one year). However, one BL patient did not go 
into reaction until he had completed 4 years of treatment, and he required strong reassurance that he had not undergone a relapse.

As a result of the reactions, LI patients usually converted to $\mathrm{BL}$ and $\mathrm{BL}$ patients to BB or even BT. The fall in the LIB as a result of the reaction was not usually so great in the early stages of treatment as in the later stages, but in almost every case it exceeded the reduction that would have been expected if there had not been a reaction. The accelerated fall in LIB did not take place until after the onset of the reaction. Thus, although there was evidence of reaction in 6 LI patients during the first year, only 3 of them showed a marked fall in the LIB during this period. There were mild lepra reactions bearing some clinical resemblance to reversal reactions in 2 of the $31 \mathrm{LL}$ patients, but as there was no change in classification as a result of the reaction, nor any unusual drop in the LIB in either of them, they are not included in the Table.

The effect of reversal reactions is also shown in Fig. 5. LI and BL patients are noticeably more erratic in their response to treatment, as judged by the LIB, than are LL patients.

\section{Erythema nodosum leprosum (ENL)}

FNL tended to occur earlier and more frequently in LL patients than in LI patients. Of the 11 LL patients studied at Sungei Buloh Leprosarium and analysed in Table 2, $8(73 \%)$ developed ENL within 12 months of commencing treatment; of the remaining 3, one subsequently developed undoubted ENL, another was seen to have one or 2 ENL-like papules at his 2-year out-patient review, which may have been a single mild episode of ENL, and only one of the 11 was never observed to develop any signs or symptoms suggestive of ENI, during a relatively brief follow-up of 25 months. On the other hand, only $17(42.5 \%)$ of the 40 LI patients developed ENL within one year of commencing treatment and a total of only $25(62.5 \%)$ were known to have suffered from ENL during more prolonged follow-up.

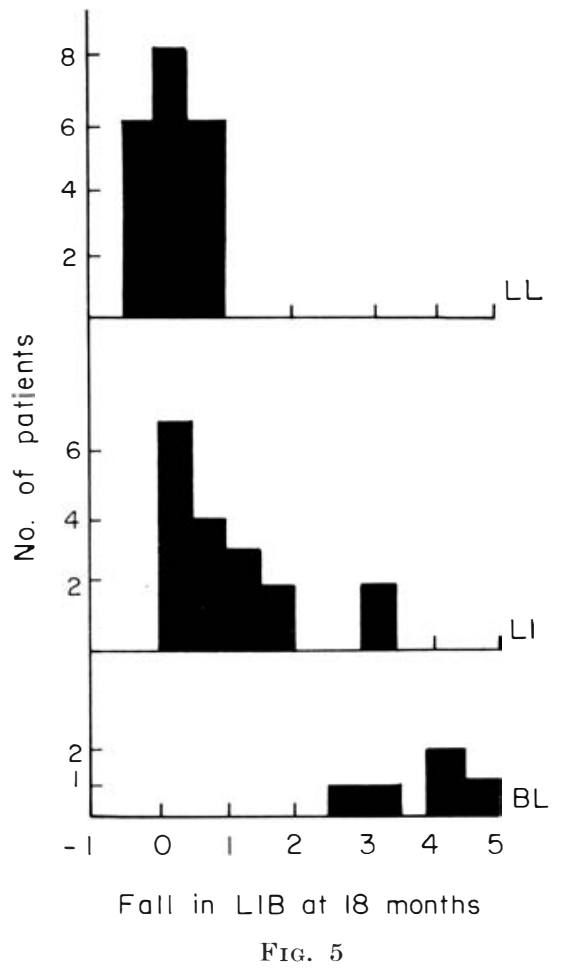

Distribution of patients according to mean fall in the LIB after 18 months' treatment; 3 groups.

ENL was least common in BL patients. Three out of 19 (i.e. 16\%) developed this type of reaction within 12 months of starting treatment, and a total of $6(32 \%)$ on more prolonged follow-up. Two BL patients who suffered from ENL subsequently underwent reversal reactions after 18 and 23 months' treatment respectively. Two LI patients who underwent reversal reactions to BL subsequently developed mild ENL. There did not appear to be any close relationship between the type of leprosy (LL, LI, or BL) and the severity of the ENL, although the duration of ENL tended to be shorter in BL leprosy; only one BL patient suffered from ENL for more than 2 years after the beginning of treatment.

Relationship of the type of leprosy and the le promin test

Pre-treatment lepromin tests were performed on all Sungei Buloh patients. No significant 
differences were discovered using Dharmendratype lepromin between LL, LI, and BL patients. When Wade-Mitsuda lepromin was used, still no significant differences were detected between LL and LI patients, who were all uniformly negative at 4 weeks; however, 3 of $9 \mathrm{BL}$ patients were weakly positive $( \pm$ or +$)$ at 4 weeks.

\section{DISCUSSION}

The analysis of lepromatous patients here reported has revealed a histologically and clinically distinctive sub-group designated indefinite leproma (LI). Prognostically, it is intermediate between $\mathrm{LL}$ and $\mathrm{BL}$ - the rate of elimination of bacilli from skin lesions, as shown by the LIB in biopsy samples, or the BI in smears, is intermediate between the other 2 groups; and a small but definite proportion of LI patients undergo reversal reactions. Histologically, the sub-group is intermediate between ILL and BL. Clinically, the great majority of LI patients bear evidence that the disease has evolved from a pre-existing borderline condition.

It has often been said that the character of lepromatous (or tuberculoid) leprosy varies in different parts of the world (Browne, 1963; Ryrie, 1948). It would appear from the foregoing that much of this geographical variation is due to small differences in the distribution of patients along the immunological spectrum; and in particular that lepromatous leprosy which has evolved from the borderline type does not frequently or quickly descend as far as the lepromatous pole (LL). It is not surprising, therefore, that the majority of lepromatous patients in Malaya (West Malaysia) are found to belong to the LI sub-group. Primary lepromatous leprosy is rare among Chinese and Malays, certainly in patients aged less than 50 years; most cases are secondary, having developed from borderline disease (Ryrie, 1948; Waters, 1967), and Maxwell and Kao (1952) considered that in no more than one of 76 lepromatous patients at Hangchow was it of the primary type. The predisposition of patients to deteriorate from non-lepromatous to lepromatous is widely recognized in the literature, and in addition to China it has been reported from India (Dharmendra, 1960), Nigeria (Davey, 1960), Europe (Medina, 1949), and South America (Souza Lima and Rath de Souza, 1949). It is clear from Table 1 that LI leprosy is less common among European patients (including those of mixed racial descent) than it is in Malaya. The number of patients of other races in this analysis is too small to give much indication of the incidence of the LT sub-group among them, but cases have been observed among Aboriginal, Indian, Gurkha, Pakistani, African Negro and Indonesian patients, and there is no reason to doubt that it occurs, in varying numbers, in all races. We are not sure how closely Leiker's "non-diffuse lepromatous (L)" group (Leiker, 1966) is related to our LI group.

We do not wish to over-emphasize the importance of the LI sub-group. It is situated very close to the lepromatous pole of the spectrum and for most purposes there is no need to distinguish between LI and LL. The prognostic differences between them are, however, of some importance in therapeutic trials. During the first 6 months of therapy there is no significant fall of the LIB in LL patients, whereas there is a very small fall in LI patients. After one year the difference in the 2 rates of fall is more marked, and is statistically significant with groups of about 20 patients. The small but definite incidence of reversal reactions will significantly affect the prognosis of individual LI patients, especially in trials of more than one year's duration. The practice, adopted at Sungei Buloh during the last 10 years, of limiting the intake of patients for trials to the LL group (Waters et al., 1967) as previously defined, has been followed also at a number of other centres. If now LI patients were to be excluded it is doubtful whether there would anywhere be a sufficient number of patients for controlled trials such as have been conducted in the past. At Sungei Buloh Leprosarium itself the number of LL patients is so small that the error of including LL and LI patients together in a single group would not be great; but ideally 
they should be separated. The problem of the analysis of results obtained from combined LL and LI groups could be overcome by using the covariance method (Waters et al., 1967), which might be considered for future trials.

It may be asked whether there is any longer any justification for using the rate of fall of the bacterial indices (LIB and BI) as a criterion of the potency of a drug. The elimination of dead leprosy bacilli has been found to be a function of the patient's immune mechanisms, and classification at the bacteriologically positive end of the spectrum has now been defined in considerable detail by reference to this fact. A correlation exists here by definition. On the other hand, none of the drugs so far used in leprosy has been shown to influence the rate of elimination of bacilli once they have been killed. The progressive fall in bacterial number is useful confirmation that bacilli have been killed and that drug resistance has not developed; it would be a criterion of potency only if a drug could be found that would hasten the process of resolution.

\section{SUMMARY}

A lepromatous sub-group (indefinite leproma, LI) has been identified histologically and clinically. The bacteriological response to treatment in this group is intermediate between that of LL and BL. LI patients differ from LL in being liable to undergo reversal reaction, though possibly at a later stage of treatment than BL patients; they differ from BL in being very prone to ENL.

The LI sub-group has been found among patients of many races, though with varying incidence. It is especially common in Chinese and Malays, among whom it greatly outnumbers LL and BL patients. LI patients are suitable for therapeutic trials under certain conditions. Clinicially, they present evidence of having evolved from a pre-existing borderline phase.

\section{ACKNOWLEDGEMENTS}

We wish to thank Dr. J. M. H. Pearson for some comments on the histology of nerves, as well as for his clinical descriptions and biopsies of certain patients; Dr. J. H. S. Pettit for a number of biopsies and clinical descriptions; and Dr. W. H. Jopling for all biopsies and smears from the Jordan Hospital patients. One of us (D.S.R.) is indebted to the Medical Research Council, London, for a grant of technical assistance in respect of the Sungei Buloh Leprosarium biopsies, and to the research funds of the Hospital for Tropical Diseases, London, in respect of the biopsies from the Jordan Hospital patients. The Leprosy Research Unit, Sungei Buloh Leprosarium, is jointly administered by the Malaysian Ministry of Health and the (British) Medical Research Council.

\section{REFERENCES}

BROWNE, S. G. (1963). The variegated pattern of leprosy. Lepra India, 35, 193.

DAVEY, T. F. (1960). Some recent chemotherapeutic work in leprosy. Trans. R. Soc. trop. Med. Hyg. 54, 199.

Dharmendra (1960). Notes on Leprosy, lst ed., p. 22. New Delhi: Ministry of Health, Government of India.

Fernandez, J. M. M., CARboni, E. A., mercaU, R. A. and SERIAL, A. (1962). Transformation of two borderline lepromatous leprosy cases to tuberculoid, with healing. Int. J. Lepr. 30, 254.

LEIKER D. L. (1966). Classification of leprosy. Lepr. Rev. 30, 7.

MAXWELL, J. L. and KAO, L. (1952). The classification of leprosy in Eastern China. Int. J. Lepr. 20, 39.

MEDINA, G. (1949). Lepra tuberculoide y lepromatosa en el mismo enfermo sobre las clasificaciones de la lepra. Int. J. Lepr. 17, 23.

Pettit, J. H. S. and Rees, R. J. W. (1967). Chemotherapeutic trials in leprosy. 4. Dapsone (DDS) in low dosage in the treatment of lepromatous leprosy. A demonstration pilot trial. Int. J. Lepr. 35, 140.

RIDLEY, D. S. (1958a). Therapeutic trials in leprosy using serial biopsies. Lepr. Rev. 29, 45.

RIDLEY, D. S. (1958b). Observations on the Prognosis of Different Classes of Leprosy in Different Races. Trans. VIIth Int. Congr. Leprol. Tokyo, p. 76.

RIDLEY, D. S. (1969). Reactions in leprosy. Lepr. Rev. 40, 77 .

RIDLEY, D. S. and HILson, G. R. F. (1967). A logarithmic index of bacilli in biopsies. 1. Method. Int. J. Lepr. 35,184 . 
RIDLEY, D. S. and JOPLING, W. H. (1962). A classification of leprosy for research purposes. Lepr. Rev. 33, 119.

RIDLEY, D. S. and JOPLING, W. H. (1966). Classification of leprosy according to immunity. A five-group system. Int. J. Lepr. 34, 255.

RYRIE, G. A. (1948). Regional differences in leprosy; leprosy among Chinese in Malaya. Lepr. Rev. 19, 4.

DE SOUZA Lima, L. and RATH DE souza, P. (1949). Pseudoexacerbation of leprosy due to the diaminodiphenyl-sulfones. Int. J. Lepr. 17, 19.
WATERS, M. F. R. (1967). Leprosy in Malaysia and South-east Asia (Guest Editorial). Int. .J. Lepr. 35, 198.

Waters, M. F. R. and pettit, J. H. S. (1965). Chemotherapeutic trials in leprosy. 2. Comparative trial of dapsone plus ditophal (Etisul) and dapsone alone in the treatment of lepromatous leprosy. Int. J. Lepr. 33, 280.

WATERS, M. F. R., REes, R. J. W. and SUtherLAND, I. (1967). Chemotherapeutic trials in leprosy. 5. A study of methods used in clinical trials in lepromatous leprosy. Int. J. Lepr. 35, 311. 